\title{
A INCLUSÃO DOS JOVENS APRENDIZES EM UMA INDÚSTRIA DO RAMO DE ALIMENTOS NA CIDADE DE PELOTAS/RS ${ }^{1}$
}

\begin{abstract}
Enio Luis Machado Lopes ${ }^{2}$
Milton Silveira dos Santos ${ }^{3}$

Francielle Molon da Silva ${ }^{4}$

RESUMO

Este trabalho pretende analisar parte do universo juvenil de Pelotas, no Rio Grande do Sul. Buscou-se compreender o processo de inserção profissional de jovens aprendizes no mercado de trabalho, especificamente em uma empresa do ramo de alimentos da cidade. O nosso principal objetivo foi compreender os dilemas que envolvem a inclusão de jovens aprendizes, considerando a perspectiva dos próprios sujeitos, da escola formadora e da empresa que participa do programa Jovem Aprendiz. Para tanto, foi realizado um estudo de caso de natureza qualitativa, a partir de entrevista com todos os envolvidos. Constatou-se como principais resultados que os jovens aprendizes, ao concluir a formação, têm expectativa de conseguir um bom emprego e que a empresa pesquisada só participa do projeto Jovem Aprendiz para atender à questão legal.
\end{abstract}

PALAVRAS-CHAVE: Inclusão de jovens; Processo de formação dos jovens aprendizes; Programa Jovem Aprendiz.

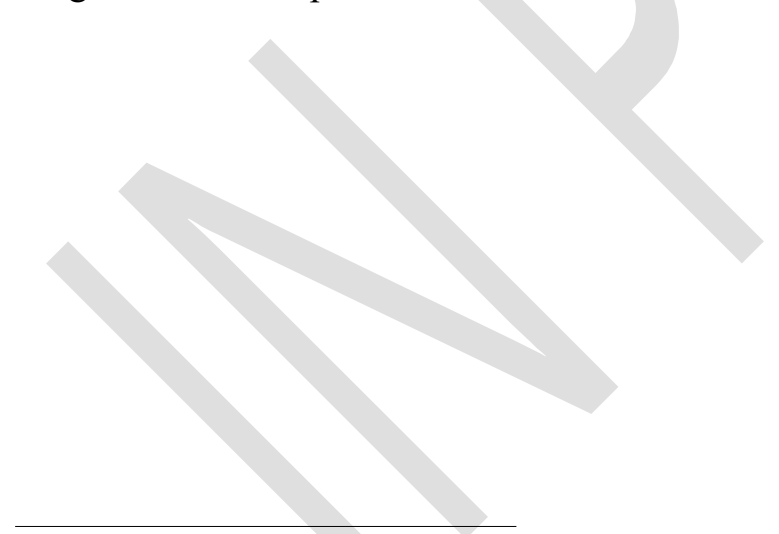

\footnotetext{
${ }^{1}$ Trabalho submetido em 07/05/18 e aprovado em 22/07/18. Para citar este artigo: LOPES, E. L. M; SANTOS; M. S.; SILVA, F. M. A inclusão dos jovens aprendizes em uma indústria do ramo de alimentos na cidade de Pelotas/RS. Cadernos de Estudos Sociais, Recife, v. 34, n. 1, p. 1-20, jan./jul. 2019. DOI: 10.33148/CES2595-4091v.34n.120191742. Disponível em: http://periodicos.fundaj.gov.br/index.php/CAD. Acesso em: dia mês, ano. [v. em edição].

2 Tecnólogo do Processos Gerenciais. Sócio administrador da Enio Informática Ltda. E Conselheiro gestor do CDL Pelotas. Universidade Federal de Pelotas (UFPel). E-mail: enil.enio@gmail.com

3 Tecnólogo do Processos Gerenciais. Gerente Comercial da Osirnt. Universidade Federal de Pelotas (UFPel). E-mail: miltonsilveiradossantos@gmail.com

${ }^{4}$ Doutora em Administração. Professora Adjunta do Departamento de Administração da Faculdade de Administração e Turismo - UFPel. Professora do Programa de Pós-Graduação em Administração FURG. Universidade Federal de Pelotas (UFPel). E-mail: franmolon@yahoo.com.br
} 


\title{
THE INCLUSION OF YOUNG APPRENTICES IN A FOOD INDUSTRY IN THE CITY OF PELOTAS/RS
}

\begin{abstract}
This paper aims at analyzing part of the juvenile universe in the city of Pelotas, in Rio Grande do Sul. We seek to understand the process of professional insertion of young apprentices in the labor market, mainly the inclusion in a company of the food industry. Our main objective was to understand the dilemmas involving the inclusion of young apprentices, considering the perspective of the subjects themselves, the trainee school, and the company participating in the Young Apprentice program. Therefore, a case study of a qualitative nature was carried out, from interviews with all those involved. As main results, we found that young apprentices, in completing the training, have the expectation of getting a good job; whereas the company researched only participates in the Young Apprentice project to comply with the legal issue.
\end{abstract}

KEYWORDS: Inclusion of young people; The training process of young apprentices; Young Apprentice Program.

\section{LA INCLUSIÓN DE JÓVENES APRENDICES EN UNA INDUSTRIA DEL RUBRO DE ALIMENTOS EN LA CIUDAD DE PELOTAS/RS}

\section{RESUMEN}

El presente trabajo pretende analizar parte del universo juvenil en la ciudad de Pelotas, en Rio Grande do Sul (Brasil). Se pretende comprender el proceso de inserción profesional de jóvenes aprendices en el mercado laboral, concretamente en una empresa del rubro de alimentos de esta ciudad. Nuestro principal objetivo fue comprender los dilemas que implica la inclusión de jóvenes aprendices, teniendo en cuenta la perspectiva de los propios sujetos, de la escuela de formación y de la empresa que participa en el programa Joven Aprendiz. Para ello, se realizó un estudio de caso de carácter cualitativo, con base en una entrevista a todos los participantes. Como principal resultado, se constató que los jóvenes aprendices, al concluir su formación, tienen la expectativa de lograr un buen empleo, mientras que la empresa analizada solo participa en el proyecto Joven Aprendiz para cumplir una exigencia legal.

PALABRAS CLAVE: Inclusión de jóvenes; Proceso de formación de los jóvenes aprendices; Programa Joven Aprendiz.

\section{INTRODUÇÃO}

Em meados da década de 1940, o país vivenciou iniciativas governamentais e de outros setores da sociedade para a inclusão massiva de jovens no mercado de trabalho (MACÊDO, 2006; PILLOTI; RIZINI, 1995). Com isso, a educação profissional formalizada funcionava com um papel disciplinador para os envolvidos. Porém. essa 


\section{CADERNOS DE}

ESTUDOS

SOCIAIS

Volume 34, número 1, jan./jul. 2019

formação não possibilitava a inserção em postos de trabalhos com bons salários. Assim não existia ascensão social e esses jovens se mantinham no mesmo ciclo de pobreza. Partindo disso, esse processo foi passando por várias mudanças ao longo dos anos, evoluindo e se ajustando. Durante esse processo a visão governamental sobre os jovens foi se alterando positivamente, chegando ao que a legislação contempla nos dias atuais, e está relatado em nossas referências.

Esse trabalho apresenta um estudo de caso sobre a inclusão dos jovens aprendizes nas empresas, tomando como referência uma indústria atuante no ramo de alimentos com sede em Pelotas, Rio Grande do Sul, e que se enquadra no que determina a SIT $n^{\circ} 97$, de 30 de julho de 2012, que trata sobre a obrigatoriedade de contratações de aprendizes. Os aprendizes pesquisados foram aqueles que já estavam participando do programa Jovem Aprendiz e a escolha da indústria de alimentos ocorreu em função do enquadramento anteriormente relatado, considerando o critério de acessibilidade.

Martins (2007) afirma que aprendiz é a pessoa com idade entre 14 e 24 anos que se submete à aprendizagem legal. De acordo com o Ministério do Trabalho e Emprego, Lei $n^{\circ} 10.097 / 2000$, ampliada pelo Decreto Federal $n^{0} 5.598 / 2005$, aprendiz é o indivíduo maior de 14 anos e menor de 24 que celebra contrato de aprendizagem, nos termos do art. 428 da Consolidação das Leis do Trabalho (CLT). Ressalta-se que a categoria aprendiz, enquanto política pública, busca formar jovens pobres para o mercado de trabalho.

Assim, este trabalho pretende analisar parte do universo juvenil de Pelotas. Busca-se compreender o processo de inserção profissional de jovens aprendizes no mercado de trabalho, especificamente na referenciada empresa. Nosso principal objetivo foi compreender os dilemas que envolvem a inclusão de jovens aprendizes, considerando a perspectiva dos próprios sujeitos, da escola formadora e da empresa que participa do programa Jovem Aprendiz. Para tanto, buscamos compreender o que leva os jovens a participarem do programa, identificar os motivos que levam a empresa a contratar um jovem aprendiz, analisar o processo de inserção e adaptação dos jovens na empresa, caracterizar o papel da entidade formadora dentro do projeto 
Jovem Aprendiz e verificar a satisfação dos jovens aprendizes e da empresa com o projeto.

Dessa forma, acredita-se que há contribuição acadêmica e social diante da disseminação do tema, sob a perspectiva dos envolvidos na política pública. Além disso, como relevância empírica, a reflexão sobre a "utilização" desse tipo de trabalho dentro das organizações, discutindo a respeito da possibilidade de desenvolvimento e aprendizagem de todos os atores participantes no processo e não apenas como atendimento à legislação vigente.

Assim, o presente artigo apresenta como justificativa colaborar para melhor entendimento a respeito do projeto Jovem Aprendiz, ampliando a discussão sobre o tema demonstrando as fragilidades e potencialidades do referido programa. Através deste, pretendemos, também, esclarecer como o projeto contribui para a formação e inclusão dos jovens no mercado de trabalho formal.

Dessa forma, abordaremos conceitos sobre a inclusão dos jovens aprendizes nas empresas, a base legal da constituição do “jovem aprendiz”, o próprio programa e, por último, a inclusão dos jovens nas organizações e o processo de qualificação. Logo, apresentamos a metodologia, demonstrando os caminhos percorridos ao longo da pesquisa, para então discutir os resultados e, por fim, as considerações finais.

\section{COMPREENDENDO O PROJETO JOVEM APRENDIZ}

Conforme consta na Lei 10.097/2000, a Convenção de Leis Trabalhistas (CLT) passaram a ter novos parâmetros a partir de 2000, por exemplo, o art. 428, que versa sobre a Lei do Aprendiz:

contrato de aprendizagem é o contrato de trabalho especial, ajustado por escrito e por prazo determinado, em que o empregador se compromete a assegurar ao maior de 14 e menor de 24 anos, inscrito em programa de aprendizagem, formação técnico-profissional metódica, compatível com o seu desenvolvimento físico, moral e psicológico. E o aprendiz, a executar, com zelo e diligência, as tarefas necessárias a essa formação (BRASIL, 2000).

Já de acordo com o Decreto $\mathrm{n}^{\circ} 6.481 / 2008$, fica proibido o trabalho, em locais e serviços considerados perigosos e insalubres a menores de 18 anos. Por outro lado, 


\section{CADERNOS DE}

ESTUDOS

SOCIAIS

Volume 34, número 1, jan./jul. 2019

nesse decreto as empresas não estão desobrigadas a matricular os aprendizes do curso em escolas formadoras. Pois, a lei proíbe o trabalho em locais perigosos e insalubres, mas não proíbe a matrícula nas escolas formadoras.

Segundo o que consta na SIT $\mathrm{n}^{\mathrm{o}}$ 97, de 30 de julho de 2012, que trata da obrigatoriedade de contratação de aprendizes, em seu artigo $2^{\circ}$, conforme determina o art. 429 da CLT, "os estabelecimentos de qualquer natureza são obrigados a contratar e matricular aprendizes nos cursos de aprendizagem, no percentual mínimo de 5 e máximo de 15\% das funções que exijam formação profissional". Diz ainda, os estabelecimentos de qualquer natureza que tenham pelo menos sete empregados são obrigados a contratar aprendizes de acordo com o percentual exigido pela lei supracitada.

De acordo com a Instrução Normativa, identificada no site do Ministério do Trabalho e do Emprego SIT $n^{\circ} 26$, incisos III e IV, do $\S 3^{\circ}$, do artigo $1^{\circ}$, o programa de aprendizagem é o conteúdo pedagógico desenvolvido por meio de atividades teóricas e práticas, sob a orientação de entidade qualificada em formação técnico-profissional metódica, devendo conter, basicamente, os objetivos do curso de aprendizagem, os conteúdos a serem ministrados e a carga horária prevista. Ainda de acordo com a IN no 26, de 20 de dezembro de 2001, cabe aos órgãos competentes como às Delegacias Regionais do Trabalho (DRTs), por meio dos Auditores do Trabalho (AFTs), fiscalizar o cumprimento das cotas de aprendizes.

Com base no exposto, podemos dizer que os parâmetros legais em relação ao projeto Jovem Aprendiz foram criados pelo governo com o intuito de qualificar e incluir profissional e socialmente, no mercado de trabalho, os jovens com idade entre 14 e 24 anos. Também tiveram o papel de determinar diretrizes a serem seguidas por todas as empresas que se enquadram no projeto, dando, dessa forma, segurança e garantias legais aos jovens.

Segundo consta no Manual de Aprendizagem do Ministério do Trabalho e Emprego, o programa Jovem Aprendiz é um programa técnico-profissional que prevê a execução de atividades teóricas e práticas sob orientação pedagógica de entidade qualificada em formação técnico-profissional metódica e com atividades práticas coordenadas pelo empregador. 
As atividades devem ter supervisão da entidade qualificadora. Nesse processo, é necessário observar uma série de fatores: público-alvo - indicando o número máximo de aprendizes por turma; perfil socioeconômico e justificativa para seu atendimento; objetivos do programa de aprendizagem, com especificação do propósito das ações a serem realizadas e sua relevância para o público participante, a sociedade e o mundo do trabalho; conteúdos a serem desenvolvidos, contendo conhecimentos, habilidades e competências, pertinência em relação aos objetivos do programa, público participante a ser atendido e potencial de aplicação no mercado de trabalho; estrutura do programa de aprendizagem e sua duração total em horas, observando a alternância das atividades teóricas e práticas, bem como a proporção entre uma e outra, em função do conteúdo a ser desenvolvido e do perfil do público participante; mecanismos de acompanhamento e avaliação do programa de aprendizagem e mecanismos de inserção dos aprendizes no mercado de trabalho após o término do contrato de aprendizagem; e o período de duração - carga horária teórica - observando a concomitância e os limites mínimo e máximo de atividades práticas, observando os parâmetros estabelecidos na Portaria MTE $\mathrm{n}^{\circ} 723$, de 23 de abril de 2012. (MANUAL DA APRENDIZAGEM, 2013, p.14).

Conforme o Manual de aprendizagem industrial do Serviço Nacional de Aprendizagem Industrial (Senai, 2015), o programa Jovem Aprendiz é o conjunto de atividades teóricas e práticas, metodicamente organizadas em tarefas de complexidade progressiva, desenvolvidas no ambiente de trabalho ( $\S 4^{\circ}$ do artigo 428 da CLT). Quantos às atividades práticas, segundo o Decreto 5.598/2005, a empresa deverá, ouvida a entidade de formação profissional, designar um monitor responsável pelo acompanhamento das atividades do aprendiz no estabelecimento. Ressalta ainda que programa de Aprendizagem não é a mesma coisa que estágio - este último é de natureza educativa, não trabalhista.

Ainda segundo o Manual de Aprendizagem Industrial do Senai, o programa Jovem Aprendiz sob a responsabilidade da instituição - realizado nas escolas mantidas pelo Senai ou em empresas e entidades a ele conveniadas -, resulta de análise minuciosa de um ofício ou ocupação para identificação dos conhecimentos, das habilidades e das atitudes requeridas do profissional e aquelas que devem ser ensinadas para atender às necessidades do setor industrial. A aprendizagem realizada 
no Senai é gratuita no atendimento aos indicados pelas empresas enquadradas em atividades industriais e aos alunos oriundos da comunidade.

Através do material pesquisado podemos observar que o projeto Jovem Aprendiz foi pensado, detalhado e determinado através da legislação nacional, para facilitar o ingresso de jovens no mercado de trabalho. Faz isso dando uma qualificação a esse jovem para, que ao final do curso na escola formadora ele esteja plenamente capaz de desempenhar uma atividade profissional.

\section{INCLUSÃO E QUALIFICAÇÃO DOS JOVENS}

A inclusão dos jovens aprendizes nas organizações através do projeto Jovem Aprendiz pode ocorrer a partir dos 14 anos. Quando inseridos no programa nessa idade, os jovens participantes passam por um processo de aprendizagem teórico e prático, agregando, dessa forma, competências técnicas que the auxiliarão no desempenho profissional.

Participando da aprendizagem profissional, o jovem é introduzido em um ambiente empresarial, com a possibilidade de mesclar a aprendizagem teórica com a prática, permitindo uma integração empresa-escola. A experiência adquirida pelo jovem durante o projeto Jovem Aprendiz poderá lhe abrir portas junto ao mercado de trabalho, pois ser mão de obra qualificada é um diferencial no momento da seleção de emprego. Com isso, Libâneo, Oliveira e Toschi (2008), relata que educação profissional deve estar integrada às diferentes formas de educação, ao trabalho, à ciência, à tecnologia e que visa o permanente desenvolvimento de aptidões para a vida produtiva.

Conforme Santiago Júnior (2007) afirma, o capital humano é o maior ativo da organização e é formado pelo conjunto de conhecimentos, habilidades e valores dos colaboradores. Para o autor, as empresas devem investir constantemente em treinamentos e programas de capacitação para suas equipes.

Segundo Saviani (2008), a educação profissional desenvolve habilidades a serem aplicadas na vida produtiva. Observa ainda que a educação profissional tem como um de seus objetivos promover a transição entre a escola e o mundo do trabalho, 
capacitando jovens e adultos com conhecimentos e habilidades gerais e específicas para o desenvolvimento de competências organizacionais.

Já para Castro, Aquino e Andrade (2008), destaca-se que a juventude foi tradicionalmente tematizada - e permanece assim até os dias de hoje - como fase transitória para a vida adulta. Por isso exigiria esforço coletivo (principalmente da família e da escola) no sentido de "preparar o jovem" para ser um adulto socialmente ajustado e produtivo, o que envolve necessariamente o emprego.

Segundo o Manual de aprendizagem industrial (SERVIÇO NACIONAL DE APRENDIZAGEM INDUSTRIAL, 2015), a aprendizagem industrial é o processo de formação profissional que visa proporcionar ao aprendiz as competências fundamentais para sua inserção no mercado de trabalho como trabalhador qualificado para atuar preferencialmente em empresas enquadradas em atividades industriais de diversos setores da economia. É destinada à formação inicial de aprendizes, segundo as diretrizes e bases legais da educação e do trabalho.

De acordo com dados retirados do site do Ministério do Trabalho e Previdência Social (MTE), foi possível identificar que a pretensão é incluir 1,7 milhão de aprendizes até 2019. Com isso pretende-se ampliar as oportunidades de qualificação profissional e de acesso ao mercado de trabalho para adolescentes e jovens, com trabalho decente e desenvolvimento social para o país. Este objetivo está fixado no Plano Plurianual 2016-2019. Nesta mesma matéria, é citado que o MTE superou, ainda no primeiro semestre de 2015, a meta do Plano Plurianual 2012-2015, que era de inserir no mercado de trabalho 1.220 .628 jovens. Em maio de 2015 foi alcançado o número de 1.286.007 aprendizes no mercado de trabalho formal. Consta ainda que, de acordo com estatísticas do MTE, mais de 50\% dos aprendizes que terminam o contrato de aprendizagem permanecem na empresa. Além disso, $84 \%$ dos jovens que participaram do projeto continuam no mundo do trabalho com contrato formal.

O projeto Jovem Aprendiz visa não só a inclusão do jovem ao mercado de trabalho, mas também contempla a formação destes jovens em um segmento de mercado específico de acordo com a escola formadora escolhida e o curso em que os mesmos estão matriculados, possibilitando capacitação profissional com formação teórica e prática, além de formar esses jovens socialmente. Para as empresas e as 
escolas formadoras, além de atender a legislação, o envolvimento com o projeto também tem caráter muito importante de cunho social.

\section{METODOLOGIA}

A pesquisa realizada se caracteriza como qualitativa de cunho exploratório, pois possibilitará a aquisição de conhecimentos através da percepção do problema apresentado. Pesquisas exploratórias têm como finalidade fazer desenvolvimento, esclarecimento e modificação dos conceitos e ideias, tendo em vista a formulação de problemas mais precisos ou hipóteses pesquisáveis para estudos posteriores. Habitualmente envolvem levantamento bibliográfico e documental, entrevistas não padronizadas e estudos de caso. Procedimentos de amostragem e técnicas quantitativas de coleta de dados não são costumeiramente aplicados nessas pesquisas (GIL, 2012).

A pesquisa classifica-se, do ponto de vista dos procedimentos técnicos, como um estudo de caso, já que tem como objetivo identificar como ocorre a relação entre os jovens aprendizes, a empresa do ramo de alimentos e a entidade formadora habilitada em um contexto espacial específico. De acordo com Yin (2005), o estudo de caso é um estudo empírico que investiga um fenômeno atual dentro de seu contexto de realidade, em que as fronteiras entre o fenômeno e o contexto não são claramente definidas e as fontes de evidências são várias.

A coleta de informações se deu a partir de entrevistas semiestruturadas gravadas com o gestor/diretor e a encarregada de Recursos Humanos da empresa de alimentos. As entrevistas foram realizadas com 11 jovens aprendizes (envolvidos no projeto e contratados desta empresa de alimentos) e com o coordenador do Curso Jovem Aprendiz da entidade formadora.

É importante ainda dizer que a empresa de alimentos possui registrados, junto à escola formadora, 14 jovens aprendizes. Os responsáveis de dois deles não autorizaram a participação na entrevista e outro evadiu do curso - ainda não tendo regularizado essa saída. As entrevistas gravadas, com as devidas autorizações (cedidas pela assinatura do termo de consentimento), foram realizadas com todos os 
envolvidos por aproximadamente três horas, com tempo médio de cinco minutos para cada jovem entrevistado e 15 minutos para os gestores. Escolhemos a empresa do ramo de alimentos pois a mesma se enquadrou no perfil desejado para nosso estudo de caso.

Vale destacar que a entrevista semiestruturada possui pouco grau de estruturação, sendo guiada por uma relação de questões de interesse a serem exploradas pelo pesquisador ao longo de seu desenvolvimento, sendo montada por pautas (GIL, 2012), o que, para fins deste estudo, demonstrou-se a técnica mais adequada.

Para tanto, foram estabelecidos três roteiros diferentes de investigação. Através do primeiro foram realizadas entrevistas individuais semiestruturadas com 11 jovens aprendizes que possuem vínculo com a empresa do ramo de alimentos, com perguntas que versavam sobre as seguintes temáticas: perfil dos jovens, motivos para entrar no projeto Jovem Aprendiz, motivo para escolher a empresa e a escola formadora, relação do jovem com a empresa, visão e a satisfação do jovem em relação ao projeto e, também, sobre a qualidade de ensino da escola formadora, direitos e deveres dos jovens aprendizes, expectativa em relação ao mercado de trabalho e, por último, se eles tinham sugestões e críticas em relação ao projeto.

Já através do segundo roteiro, realizamos uma entrevista com o coordenador da escola formadora com a intenção de entender se a escola formadora consegue atender a demanda de jovens aprendizes; como é feito o processo de seleção dos jovens aprendizes que participam do projeto pela escola; qual o tempo de duração do curso; se na escola os cursos oferecidos para o projeto possuem algum segmento ou setor como foco de aprendizagem; qual a opinião dele sobre os conteúdos que são ministrados; se existem problemas na relação entre empresa e jovens aprendizes; se os jovens aprendizes que se formam alcançam o objetivo do projeto Jovem Aprendiz e saem empregados; se a escola possui acompanhamento sobre a inserção no mercado de trabalho dos Jovens egressos do curso; e as sugestões e críticas dele em relação ao projeto.

Através do terceiro roteiro, foram realizadas entrevistas com o gestor/diretor e com a encarregada de Recursos Humanos da empresa de alimentos com intuito de saber por que a empresa contrata jovens aprendizes; como funciona o processo de 


\section{CADERNOS DE}

ESTUDOS

SOCIAIS

Volume 34, número 1, jan./jul. 2019

seleção dos jovens; se os jovens formados são aproveitados na empresa; se eles consideram importante a formação dada pela escola; qual a opinião deles em relação ao objetivo do projeto Jovem Aprendiz; quais funções os jovens desenvolvem quando estão à disposição da empresa; qual a opinião deles em relação ao conteúdo aplicado na escola formadora; quais fiscalizações a empresa realizou em relação aos jovens aprendizes; e se eles tinham sugestões e críticas em relação ao projeto Jovem Aprendiz.

De posse dos dados, foi utilizada como técnica de análise a triangulação dos mesmos com a teoria apresentada no presente artigo anteriormente. As falas dos jovens serão apresentadas sem identificação dos mesmos, apenas relatando Jovem 01, Jovem 02. Já os demais relatos serão identificados a partir dos cargos assumidos tanto na escola formadora quanto na empresa investigada.

Dessa forma, a próxima seção visa apresentar, primeiramente, a percepção dos jovens. Logo após, traz a visão da empresa. Por fim, as colocações provenientes da escola formadora. Lembrando que sempre que possível foram estabelecidas relações entre as percepções dos diferentes atores envolvidos bem como utilizou-se a técnica de triangulação de dados para interpretar os resultados. Essas relações serão melhor exploradas nas considerações finais.

\section{ANÁLISE DOS DADOS}

Nesta parte do estudo serão apresentados e discutidos os resultados encontrados nas entrevistas. Conforme apontamos na metodologia, a opção é apresentar as percepções dos diferentes sujeitos entrevistados separadamente.

\subsection{Análise da percepção dos jovens aprendizes: uma investigação frente aos dilemas que envolvem a atuação dos mesmos dentro do projeto}

Os jovens aprendizes pesquisados estão na faixa etária de 14 a 18 anos - sete destes jovens são do sexo masculino e quatro do sexo feminino. Três dos jovens já concluíram o ensino médio e os demais estão cursando entre o $7^{\circ}$ e $8^{\circ}$ ano. 
Ao que se refere aos motivos que os levaram a ingressar no projeto, sete deles, sinalizaram o fato de contribuir para sua qualificação e aprendizagem, bem como a possibilidade de encontrar uma profissão. O Jovem 02 cita "mais para ter um currículo, assim, aprender um pouco"; o Jovem 03 considera "a qualificação, o mercado de trabalho"; e o Jovem 05 aponta que "uma parte que me levou é que eu queria pegar um ramo e aí saiu esse curso aí. Vim em busca de uma profissão".

Assim, percebemos que a motivação dos jovens aprendizes para ingresso no projeto se dá principalmente pela busca de aprendizado, qualificação, um futuro melhor e ingresso no mercado de trabalho. Isso vai de encontro ao que foi apontado anteriormente por Libâneo, Oliveira e Toschi (2008).

Já em relação aos motivos para serem contratados pela empresa de alimentos para participar do projeto e estar matriculados na escola formadora, os jovens afirmam: "Meu tio trabalha na empresa de alimentos e segurou a vaga pra mim" (Jovem 06); "Minha mãe trabalha lá e me indicou” (Jovem 08); “Eu, fui procurando empresas que necessitavam de jovens, e com essa procura, a empresa de alimentos me abriu as portas. Não conhecia ninguém de lá” (Jovem 09).

Pode-se perceber que sete, uma maioria, dos jovens contratados pela empresa de alimentos que estão matriculados na escola formadora são selecionados por possuir algum vínculo familiar e/ou de amizade com funcionários da empresa - ou seja, por indicação. A empresa com o método utilizado para seleção atende o que determina o artigo 429 da CLT:

Os estabelecimentos de qualquer natureza são obrigados a contratar e matricular aprendizes nos cursos de aprendizagem, no percentual mínimo de 5 e máximo de $15 \%$ das funções que exijam formação profissional. Diz ainda que os estabelecimentos de qualquer natureza que tenham pelo menos sete empregados são obrigados a contratar aprendizes de acordo com o percentual exigido por lei. (ARTIGO 429, CLT).

Sobre a relação do jovem aprendiz com a empresa e se eles desempenham alguma função dentro da empresa de alimentos, o Jovem 03 diz: "Não, lá eu só vou lá para assinar o contracheque"; já o Jovem 04 cita: "Que eles me falaram que não. Eu, só fico aqui no Senai"; e o Jovem 06 complementa dizendo que: "Não, só faço o curso". 


\section{CADERNOS DE}

ESTUDOS

SOCIAIS

Volume 34, número 1, jan./jul. 2019

Devido ao fato de empresa de alimentos ser uma indústria insalubre, empregadores e aprendizes respeitam e atendem o Decreto $\mathrm{n}^{\circ}$ 6.481/2008: fica proibido o trabalho em locais e serviços considerados perigosos e insalubres a menores de 18 anos. Por outro lado, neste decreto as empresas não estão desobrigadas a matricular os aprendizes no curso em escolas formadoras. A lei proíbe o trabalho em locais perigosos e insalubres, mas não proíbe a matrícula nas escolas formadoras. Por isso, os jovens realizam suas atividades somente na escola formadora.

Sobre a visão dos aprendizes em relação à participação no projeto e se isso será um diferencial em futuras contratações, o Jovem 02 cita: "Pra mim? Eu acho que sim. Porque o Senai prepara um pouco de técnicas, e já é um ambiente de trabalho. Daí tu já vai se acostumando desde cedo" e o Jovem 09 fala que:

Com certeza, porque, comparando a nossa escolaridade, o que a gente aprende aqui, com as pessoas que não tem esse tipo de curso, é quase, não tem concorrência quase. $\mathrm{O}$ que a gente aprende aqui dentro é completamente diferente do que se aprende lá fora.

Assim, podemos perceber que os jovens entrevistados valorizam a participação no projeto devido à possibilidade de ter mais experiência, qualificação melhor e pela oportunidade de entrar no mercado de trabalho. Situação que converge com o que afirma Saviani (2008), a educação profissional desenvolve habilidades a serem aplicadas na vida produtiva.

Em relação à satisfação dos jovens, questionamos se eles indicariam a participação no projeto para seus amigos ou parentes, e o Jovem 05 responde: "Sim, por que é bom. É uma coisa que vai para o futuro"; já o Jovem 08 diz: "Indicaria, porque é bom, é legal, uma coisa para ocupar o seu dia a dia"; e o Jovem 11 afirma: "Sim, porque dá bastante oportunidades depois com o curso".

É nítida a satisfação dos 11 aprendizes entrevistados em relação ao que é ministrado nos cursos que eles participam no projeto Jovem Aprendiz. Relatam que o curso ajuda a amadurecer, gera novas oportunidades, possibilita qualificação e dá experiência. Desta forma, constatamos que a escola formadora atende o que consta no Manual de aprendizagem industrial (SERVIÇO NACIONAL DE APRENDIZAGEM 
INDUSTRIAL, 2015) sobre a formação inicial dos aprendizes, considerando bases legais de educação e trabalho.

Sobre o conhecimento dos direitos e deveres que os jovens aprendizes têm ao participar do projeto, o Jovem 04 diz: "Não. Já tive interesse em pesquisar, mas não dá tempo, aqui é todo dia"; o Jovem 07 responde: "Eu conheço poucos... mas, não lembro para citar"; e o Jovem 09 cita que: “Quando entra no curso a gente recebe as normas pra cá pra dentro e no contrato eles expõem os direitos que a gente tem como empregados e os deveres que os empregadores tem para conosco".

Podemos notar que a maioria (6) dos alunos entrevistados não tem preocupação em relação a seus direitos e deveres, tanto que estes afirmaram não conhecer ou não lembrar de seus direitos e deveres. Desta forma, a Lei 10.097/2000 e a CLT passam a ter novos parâmetros a partir do ano 2000, como, por exemplo, o art. 428, que versa sobre a Lei do Aprendiz:

Contrato de aprendizagem é o contrato de trabalho especial, ajustado por escrito e por prazo determinado, em que o empregador se compromete a assegurar ao maior de 14 e menor de 24 anos, inscrito em programa de aprendizagem, formação técnico-profissional metódica, compatível com o seu desenvolvimento físico, moral e psicológico. E o aprendiz, a executar, com zelo e diligência, as tarefas necessárias a essa formação. (BRASIL, 2000).

Essa passa praticamente despercebida pelos jovens entrevistados.

Sobre a expectativa dos aprendizes em relação ao mercado de trabalho, o Jovem 01 afirma: "Expectativa é achar um trabalho bom, porque eu já tenho experiência"; o Jovem 06 diz que: "Eu, queria sair trabalhando na empresa de alimentos"; e o Jovem 11: "É de conseguir um emprego bom, com esse curso pra mim é”.

Os jovens, na sua totalidade, vislumbram com o término do curso no projeto Jovem Aprendiz estar trabalhando ou estar qualificados para entrar em uma faculdade. Com isso, caso consigam se manter empregados, se enquadrarão naquilo que o MTE cita na matéria publicada em seu site: mais de 50\% dos aprendizes que terminam o contrato de aprendizagem permanecem na empresa. Além disso, $84 \%$ dos jovens que participaram do projeto continuam no mundo do trabalho, com contrato formal. 


\section{CADERNOS DE}

ESTUDOS

SOCIAIS

Volume 34, número 1, jan./jul. 2019

Em relação a sugestões e críticas acerca do projeto Jovem Aprendiz, o Jovem 01 diz: "Pelo que eu vi até agora, está tudo bom"; já o Jovem 05 diz: "Eu, gostei deste jeito. Para mim não precisa mudar nada"; e o Jovem 10: "Acho que o plano de saúde, porque a gente não tem plano de saúde".

Com exceção de dois jovens aprendizes que citam como sugestão a inclusão do plano de saúde, os demais jovens apresentam total satisfação com a metodologia e as rotinas aplicadas no curso. Inclusive, nenhum deles apresentou críticas ao projeto. Dessa forma, o que consta na IN/MTE/SIT n ${ }^{\circ} 26$, incisos III e IV, do $\S 3^{\circ}$, do art. $1^{\circ}$,

O programa de Aprendizagem é o conteúdo pedagógico desenvolvido por meio de atividades teóricas e práticas, sob a orientação de entidade qualificada em formação técnico-profissional metódica, devendo conter, basicamente, os objetivos do curso de aprendizagem, os conteúdos a serem ministrados e a carga horária prevista, atende perfeitamente as expectativas e anseios dos jovens aprendizes.

\subsection{A consideração da escola formadora: uma análise considerando a percepção do coordenador da escola formadora}

O coordenador da escola formadora tem 38 anos de idade e está na função, trabalhando na escola, há 11 anos. Ao iniciar a entrevista, questionamos se a escola formadora consegue atender a demanda de jovens aprendizes que as empresas da região necessitam e ele respondeu que "Consegue, na verdade a gente [...] só trabalha sob demanda, se tiver necessidade, a gente tem aprendizagem".

Dessa forma, a escola formadora atende o que consta no Manual de Aprendizagem Industrial do Senai. O programa Jovem Aprendiz, quando sob responsabilidade desta instituição, é realizado através de escolas mantidas pelo próprio serviço ou de empresas e entidades a ele conveniadas. O ensino é resultado da análise minuciosa de um ofício ou ocupação para identificação de conhecimentos, habilidades e atitudes requeridas do profissional para atender às necessidades do setor industrial.

Sobre como é feito o processo de seleção dos jovens aprendizes que participam do projeto, o coordenador da escola formadora cita: 
Hoje em dia a maioria dos alunos vem por indicação - é a empresa que seleciona e nos encaminha. Temos algumas turmas que são projetos juntos com o Sesi, nas quais o serviço seleciona, porque ele tem outra característica - a parte social, também -, e aí, por esse programa conjunto, a gente encaminha [a proposta] para as empresas perguntando se as elas tem a necessidade de aprendizes e se importam em contratar estes jovens que já foram selecionados, mas na sua maioria são alunos indicados pela indústria.

Tratando do tempo de duração do curso na escola formadora, o coordenador afirma durar no máximo dois anos. Contudo, algumas turmas e alguns cursos duram menos, variando entre um e dois anos. Este tempo de duração atende o que consta no Manual de Aprendizagem do MTE. Nele o período de duração (carga horária teórica) é defenido observando a concomitância e os limites mínimos e máximos das atividades práticas, delimitados pela Portaria MTE nº 723, de 23 de abril de 2012.

Ao ser questionado se o projeto de formação dos jovens aprendizes possui um segmento/setor como foco de aprendizagem o coordenador da escola responde:

$\mathrm{Na}$ verdade é de acordo com a disponibilidade da indústria. Nós temos aqui basicamente os cursos de mecânica, elétrica e panificação/confeitaria. Já tivemos construção civil - aprendizagem de construção civil -, temos também assistente administrativo. Dentro da mecânica são duas modalidades: o mecânico de manutenção e o mecânico de usinagem, que se diferem um pouco. Mas [o objetivo maior] desses cursos de mecânica e elétrica [...] é a manutenção, porque [é um] setor [...] que todas as empresas possuem - ou, de certa forma, todas possuem equipamentos e máquinas que podem necessitar de manutenção.

Já em relação à existência de problemas entre empresa e jovens aprendizes, o coordenador fala:

Não, não. No caso da empresa de alimentos, só para comentar os cursos que eles estão cursando agora, são alunos basicamente de mecânica de usinagem, mecânica de manutenção e elétrica e esses alunos, por ser menores de idade, ou por estarem em um programa feito para menores não podem ir para a indústria, então eles fazem todo o programa de aprendizagem aqui na escola, não há a prática educativa na empresa.

Com isso, podemos notar que devido às proibições indicadas no Decreto $\mathrm{n}^{\circ}$ 


\section{CADERNOS DE}

ESTUDOS

SOCIAIS

Volume 34, número 1, jan./jul. 2019

$6.481 / 2008$, a empresa tem pouco ou quase nenhum contato com esses jovens aprendizes.

Em relação ao sucesso do do projeto Jovem Aprendiz - a inserção do jovem no mercado de trabalho - o coordenador responde:

Eu estive em Porto Alegre em uma reunião da coordenação do estado e há [...] 55\% de absorção dos jovens nas profissões para as quais se formaram [...] Esse número já foi maior, [ele] vem caindo muito em função de hoje a empresa, [influenciada pelo] nosso sistema de seleção, provavelmente, [...] indicar os filhos de funcionários. Enfim, daqui a pouco o jovem não está, digamos, interessado em continuar essa profissão dentro da empresa.

Pode-se notar que esse número de $55 \%$ dos alunos, em nível estadual, serem absorvidos pelo mercado de trabalho está bem abaixo dos indicadores divulgados no site do Ministério do Trabalho e Emprego.

A respeito de a escola formadora possuir algum acompanhamento da inserção dos egressos no mercado de trabalho, o coordenador fala:

Existe essa pesquisa em nível de estado - a gente tem, na verdade, uma orientação a nível nacional. No Senai, o nosso departamento nacional tem um sistema chamado SAPS, que é um sistema de avaliação de egressos do Senai [...]. Então todo o aluno que se forma, no final do curso, faz uma avaliação, preenche um cadastro a nível nacional via internet e, depois de um ano, a empresa e o Senai, por amostragem, ligam para estes alunos [...], fazendo uma entrevista [...] [Pergunta-se] se ele está empregado. [Também] fazemos uma entrevista com o empregador. E depois, com um ano a mais - dois anos depois de formado -, novamente ligamos para este egresso e para empresa em que ele está trabalhando.

Com esse sistema utilizado pela a escola formadora, o que consta no Manual de Aprendizagem do MTE em relação à escola possuir mecanismos de acompanhamento e avaliação do programa de aprendizagem e mecanismos de inserção dos aprendizes no mercado de trabalho após o término do contrato de aprendizagem é atendido corretamente.

Ao ser questionado se possuía alguma sugestão de melhoria para o projeto Jovem Aprendiz, o coordenador relata: 
Eu acho que a principal melhoria do Jovem Aprendiz já está sendo retomada, na verdade. É uma prática que existia no passado com bastante força e por força de lei acabou sendo abandonada. É a questão da prática na empresa. O Senai, há poucos anos trabalhava [com um sistema em que] todos os alunos tinham que fazer práticas na empresa. Depois, com a questão do entendimento das leis de que um aluno de 17 anos, menor de idade, está dentro de um ambiente fabril... [Por] essas questões trabalhistas, o Senai acabou não tendo mais como fazer essa prática na empresa. Com isso, toda a prática é transferida para dentro do Senai. Agora está sendo feito todo um trabalho a nível nacional - e aqui no Rio Grande do Sul também -, de conversa, de acerto, por exemplo com a Secretaria Regional do Trabalho e também com as empresas pra que a gente consiga fazer turmas e/ou boa parte das nossas turmas possam voltar a ter práticas na empresa. Isso vai transformar a aprendizagem, pelo menos dentro do Senai.

E, com relação às críticas ele responde:

A crítica que eu faço é essa de que, como bons brasileiros que somos, a gente procura sempre enxergar o problema primeiro. Então a gente enxerga a aprendizagem, a sociedade, a indústria, o comércio, enfim... De forma geral se enxerga a aprendizagem como um custo, um peso para a indústria - eu acho que a grande crítica é essa ter a oportunidade pra que a gente possa mudar essa mentalidade.

Conforme citado pelo coordenador, a empresa está em tratativa com os órgãos competentes a fim de os jovens aprendizes ter aulas práticas dentro de si. Dessa forma, deverão buscar alguma alternativa, vistas as proibições do Decreto $n^{0}$ 6.481/2008. Já no que tange à crítica, as empresas poderiam levar em consideração o que afirma Santiago Júnior (2007), o capital humano é o maior ativo da organização e é formado pelo conjunto de conhecimentos, habilidades e valores dos colaboradores e as empresas devem investir constantemente em treinamento e programas de capacitação das suas equipes.

\subsection{A visão da empresa sobre o projeto: considerações dos gestores}

As entrevistas com os gestores da empresa estudada ocorreram com o gestor/diretor e com a encarregada de Recursos Humanos da empresa, sendo que essa última está na empresa há cinco meses. 


\section{CADERNOS DE}

ESTUDOS

SOCIAIS

Volume 34, número 1, jan./jul. 2019

Iniciamos nossa entrevista questionando a eles qual o motivo de a empresa contratar jovens aprendizes. A resposta do diretor foi: "por obrigação legal". A encarregada de Recursos Humanos respondeu no mesmo sentido: "olha, pelo que eu soube de início, em um primeiro momento foi pra contemplar a legislação". Desta forma, devido à questão legal e à obrigatoriedade, eles atendem o que determina o artigo 429 da CLT.

Ao complementarmos a questão anterior e questionarmos se eles contratariam jovens aprendizes se não existisse a questão legal, ambos foram taxativos e responderam: "não".

Desta forma, a empresa não considera a questão da formação dos jovens aprendizes na escola formadora e acaba por desconsiderar também o que cita Saviani (2008), que a educação profissional desenvolve habilidades a serem aplicadas na vida produtiva, conforme apontado em nosso referencial e já mencionado na interpretação com relação às contribuições do coordenador da escola formadora.

Sobre como é feito o processo seletivo dos jovens na empresa, o diretor responde: "a gente procura entre os funcionários [quem tem] filhos para que possam indicar como jovens aprendizes". A encarregada de recursos humanos complementa:

A gente não tem, pelo que eu sei, [...] um processo estruturado. O que a gente faz é dar prerrogativa se houver interesse de alguém da empresa que tenha algum filho, algum sobrinho, alguém da família que tenha interesse. São colocados, também, avisos nos painéis quando a gente tem vagas pra também eles divulgarem entre si, para informar as pessoas que tiverem interesse em se candidatar à vaga. Mais ou menos desta forma que funciona.

Como o artigo 429 da CLT trata somente da obrigatoriedade da contratação e da consequente matrícula dos jovens aprendizes na escola formadora, sem abranger nada sobre o processo seletivo, a empresa direciona as vagas para os familiares dos funcionários da própria empresa de forma legal.

Ao questionarmos se a empresa efetiva os jovens aprendizes que possuem vínculo com ela ao se formar no projeto jovem aprendiz, o diretor fala que "nenhum" 
e a encarregada de Recursos Humanos respondeu: "como empregado não tenho conhecimento".

Como o foco da empresa é atender a questão legal, não resultando em emprego efetivo depois, os jovens aprendizes acabam por não se encaixar nos indicadores divulgados pelo MTE.

Em relação à formação dos jovens aprendizes junto à escola formadora, quando questionamos se isso pode ser um diferencial em uma seleção realizada pela empresa, o diretor responde: "Não. Hoje, não considera" e a encarregada de RH fala: "Eu, acho que isso não é significativo".

Mesmo que a escola formadora trabalhe para atender o que consta no Manual de Aprendizagem Industrial do Senai essa formação acaba não sendo levada em consideração pela empresa.

Ao ser questionado se concorda com o objetivo do projeto, o diretor da empresa responde: "Pelo conhecimento que a gente tem até agora, a gente não concorda". A encarregada do RH disse: "Desde que preencha os requisitos que nós estávamos falando agora a pouco”. Requisitos destacados como idade mínima e renda.

Mesmo com o processo de formação que o jovem aprendiz passa, preparando-se para o mercado de trabalho de acordo com o sistema que consta no Manual de Aprendizagem do MTE - a empresa não considera o processo e a qualificação como portas de entrada para o mercado de trabalho.

Ao questionarmos sobre as funções desempenhadas pelos jovens aprendizes quando à disposição da empresa, o diretor respondeu: “A gente não utiliza o tempo que poderia utilizar com o jovem aprendiz, até porque a legislação não permite, por se tratar de uma indústria" e a encarregada de Recursos Humanos falou: "Não, os cursos que nós tivemos até o momento não permitem atividades dentro da empresa. Então a gente não teve as práticas".

Ao ser questionado se, na visão da empresa, o conteúdo aplicado no projeto Jovem Aprendiz para os jovens que possuem vínculo com a empresa é adequado, o diretor diz: "A gente não tem conhecimento"; e a encarregada de RH complementou dizendo: "Não. Eu, não tenho conhecimento desta parte que eles desenvolvem lá no Senai". 


\section{CADERNOS DE}

ESTUDOS

SOCIAIS

Volume 34, número 1, jan./jul. 2019

Em relação ao questionamento sobre o recebimento de fiscalização para verificar a situação dos jovens aprendizes, ambos afirmaram frequência desse procedimento.

Pela afirmação dos gestores da empresa, pode se confirmar que o que consta na $\mathrm{IN} \mathrm{n}^{\mathrm{o}} 26$ - que cabe aos órgãos competentes, como às Delegacias Regionais do Trabalho (DRTs), por meio dos Auditores do Trabalho (AFTs), fiscalizar o cumprimento das cotas de aprendizes - está sendo cumprido.

Já sobre sugestões e críticas em relação ao projeto Jovem Aprendiz, o diretor disse: "Imagino que sim, mas agora não", como forma de sugestão. Sobre as críticas: "A crítica só que, da forma como a empresa entende hoje, é mais só uma obrigação legal”. Já a encarregada de recursos humanos, em relação à sugestão, cita: "que haja um curso que deixe essas pessoas preparadas para o mercado de trabalho e que o mercado de trabalho absorva essas pessoas, que é fundamento do programa". Sua crítica é "no sentido de que, é aquela coisa, o que vem pra bem, tem que funcionar bem. E nem sempre é assim que funciona".

Através das palavras dos gestores da empresa, podemos notar que ela atende à SIT no 97/2012, porém não aceita essa obrigatoriedade e o projeto Jovem Aprendiz como um todo.

\section{CONSIDERAÇÕES FINAIS}

Após a coleta de dados com os envolvidos, podemos destacar, no que se refere aos jovens aprendizes, além do que já foi citado em nosso trabalho, que, inicialmente, esses jovens aderem ao projeto pela remuneração. Porém, com o passar do tempo, acabam identificando-se com o conteúdo e a parte prática do curso, que tem por objetivo direcionar o jovem para uma formação profissional. Identificação essa que acaba ocasionando numa total satisfação com o projeto e, principalmente, com a escola formadora. Mesmo aqueles que não pretendem seguir a profissão para a qual estão se capacitando no curso destacam que o aprendizado recebido acabará sendo um diferencial em futuras contratações ou até mesmo em processos seletivos para formação superior. 
Devido à restrição legal, que não permite o trabalho dos jovens em ambiente insalubre, esses estudantes não tem um contato muito próximo com a contratante, se relacionando basicamente com a escola formadora, desconhecendo, assim, as rotinas e o ramo de atividade desenvolvido pela empresa.

Para empresa, que realiza as contratações dos jovens aprendizes somente para atender à questão legal, fica claro que o projeto é um problema. Para eles, apresenta custo alto sem retorno aparente. Devido a essa "insatisfação" acaba não valorizando a formação recebida pelos jovens aprendizes, tratando a situação de forma indiferente. Inclusive os gestores desconhecem totalmente o que é aplicado e o resultado alcançado pela escola formadora junto aos jovens, pois consideram que os cursos aplicados não se enquadram na formação profissional de sua indústria. Inclusive, se não fosse pela obrigatoriedade, a empresa de alimentos não contrataria jovens aprendizes em nenhuma hipótese, conforme os dados apresentados. Assim, mesmo eles sendo a empresa responsável pelo investimento na formação do jovem aprendiz, acabam preparando esses jovens para trabalhar em outras empresas.

No que refere à escola formadora, vale destacar a estrutura física e de pessoal. $\mathrm{Na}$ pesquisa observou-se que esses elementos eram satisfatórios sob o ponto de vista de aprendizagem. Ainda pudemos verificar que a escola apresenta políticas de educação claras que são compartilhadas pelos próprios alunos e vistas como elementos facilitadores e estimulantes para o desenvolvimento.

Podemos destacar, dessa forma, que nosso trabalho contribui para o tema de pesquisa "a inclusão de jovens aprendizes nas empresas" em relação à questão da satisfação dos jovens em relação à formação oferecida pela escola, mas principalmente à qualidade do ensino e à formação social e profissional. Isso contribui para a inclusão destes jovens no mercado de trabalho, mesmo que não seja na empresa na qual possuem vínculo atualmente.

Sobre a relevância de nossa pesquisa, podemos destacar algumas situações importantes em relação aos sujeitos investigados: (1) Ao tomarem conhecimento da pesquisa realizada por nós, jovens que ainda não participam do projeto, mas se enquadrem na idade de 14 a 24 anos podem se sentir estimulados a entrar, pois retratamos, através da entrevista realizada com os jovens aprendizes, qual seu nível de satisfação em relação ao projeto e à escola formadora. Além disso, apontamos 


\section{CADERNOS DE}

ESTUDOS

SOCIAIS

Volume 34, número 1, jan./jul. 2019

possibilidades futuras que essa formação poderá proporcionar. (2) Já em relação à empresa, como eles desconheciam totalmente como se dá o processo de ensino e formação dos jovens aprendizes, tivemos a oportunidade de destacar que, mesmo sendo uma obrigatoriedade a contratação dos jovens, dentro da escola a formação social e profissional é de extrema qualidade e satisfaz os contratados. (3) Para escola, acreditamos que a situação mais positiva é poder demonstrar que todo o processo de ensino aplicado junto aos jovens aprendizes está gerando bons resultados - que além de estarem conseguindo transmitir conhecimento, estão formando pessoas e bons profissionais. E ainda, os jovens demonstram total satisfação por todo esse processo.

Fica registrada também nossa crítica em relação ao projeto Jovem Aprendiz no que diz respeito à proibição legal de os jovens realizarem atividades em empresas insalubres, pois dessa forma estes jovens ficam distantes da realidade da empresa e principalmente do convívio com profissionais.

Para finalizar, destacamos que conseguimos visualizar bom funcionamento do projeto Jovem Aprendiz no que diz respeito à formação dos jovens aprendizes para a indústria, porém seria muito importante que esse tipo de estudo tivesse uma evolução e que fossem realizadas outras pesquisas buscando entender esse processo em outros segmentos profissionais, constatando, assim, como essas relações acontecem e até mesmo confrontando a formação dos jovens em outro segmento com os que se formam em uma escola ligada a indústria. Ou seja, sugerimos para pesquisas futuras: ampliação em termos de segmentos e escolas formadoras; discussão sobre os aspectos que colaboram com o desenvolvimento dos jovens em prol de sua inserção no mercado de trabalho; e debate a respeito da conformidade e contribuição de políticas públicas diante da qualificação da juventude brasileira e de sua relação com a empregabilidade desses jovens.

\section{REFERÊNCIAS}

BRASIL. Lei ${ }^{\circ} 10.097$, de 19 de dezembro de 2000. Altera dispositivos da

Consolidação das Leis do Trabalho - CLT, aprovada pelo Decreto-Lei no 5.452, de 10 de maio de 1943. Diário Oficial da União, Brasília, DF, 20 dez. 2000. Disponível em: https://bit.ly/2NKbJAx. Acesso em: 17 dez. 2018. 
CASTRO, J. A.; AQUINO, L. C. M.; ANDRADE, C. C. Juventude e políticas sociais no Brasil. Brasília: Instituto de Pesquisa e Economia Aplicada, 2008.

GIL, A. C. Métodos e técnicas de pesquisa social. São Paulo: Atlas, 2012.

LIBÂNEO, J. C.; OLIVEIRA, J.F.; TOSCHI, M.S. Educação escolar: políticas, estrutura e organização. 6. ed. São Paulo: Cortez, 2008.

MACÊDO, O. J. V. O sentido da formação para o trabalho e as expectativas em relação ao futuro por parte dos adolescentes aprendizes. 2006. $181 \mathrm{f}$. Dissertação (Mestrado em Psicologia Social) - Universidade Federal da Paraíba, João Pessoa, 2006.

MANUAL DA APRENDIZAGEM. O que é preciso para contratar o aprendiz. Ed. rev. e ampl. Brasília: Ministério do Trabalho e Emprego, 2013. Disponível em: https://www.ipt.br/download.php?filename=1031-Manual_da_Aprendizagem_ 2013. pdf. Acesso em: 15 mar. 2016.

MARTINS, S. P. Direito do trabalho. São Paulo: Atlas, 2007.

PILLOTTI, F.; RIZZINI, I. A arte de governar crianças: a história das políticas sociais, da legislação e da assistência à infância no Brasil. Rio de Janeiro: Universidade Santa Úrsula, 1995.

SANTIAGO JÚNIOR, J. R. S. Capital: o grande desafio das organizações. São Paulo: Novatec, 2007.

SAVIANI, D. Da nova LDB ao FUNDEB: por uma política educacional. 3. ed. Campinas: Autores Associados, 2008. (Coleção Educação Contemporânea).

YIN, R. K. Resenha livre. Porto Alegre: Bookman, 2005. 